\title{
The Inhibition Site on Myelin-Associated Glycoprotein Is within Ig-Domain 5 and Is Distinct from the Sialic Acid Binding Site
}

\author{
Zixuan Cao, Jin Qiu, Marco Domeniconi, Jianwei Hou, J. Barney Bryson, Wilfredo Mellado, and Marie T. Filbin \\ The Department of Biological Sciences, Hunter College, City University of New York, New York, New York 10021
}

\begin{abstract}
Myelin-associated glycoprotein (MAG) is a potent inhibitor of axonal regeneration. It contains five Ig-like domains and is a sialic binding protein. Previously, we showed that the sialic acid binding site on MAG maps to arginine 118 in Ig domain 1 (Kelm et al., 1994). However, sialic acid binding was neither necessary nor sufficient for MAG to bring about inhibition of neurite outgrowth. Consistent with this, we now map a distinct inhibition site on MAG to Ig domain 5 (Ig-5). We show that when a truncated form of MAG missing Ig domains 1 and 2 is expressed by Chinese hamster ovary ( $\mathrm{CHO}$ ) cells, it does not bind sialic acid, but still inhibits neurite outgrowth almost as effectively as full-length MAG. To determine whether the inhibition site mapped to Ig-3, Ig-4, or Ig-5, we made chimeric molecules of various combinations of these three MAG Ig domains fused to Ig domains from another Ig family member, sialoadhesin ( $\mathrm{Sn}$ ), which also binds to sialic acid in the same linkage as MAG. The MAG-Sn molecules were expressed in CHO cells and all contained five Ig domains and were able to bind sialic acid. However, only the chimeric molecules containing MAG Ig-5 inhibited neurite outgrowth. Furthermore, peptides corresponding to sequences in MAG Ig-5, but not Ig-4 or Sn Ig-5, are able to block inhibition of neurite outgrowth by both wild-type MAG and CNS myelin. We conclude that the inhibition site on MAG is carried by Ig domain 5 and that this site is distinct from the sialic-acid binding site.
\end{abstract}

Key words: MAG; binding domain; axon growth; guidance; myelin; regeneration

\section{Introduction}

Myelin-associated glycoprotein (MAG) is found in both the PNS and CNS myelin (Trapp, 1990). It is one of the first proteins to be expressed when myelination commences and is located in the first myelin wrap around the axon, as well as in areas of uncompacted myelin such as the paranodal loops (Trapp, 1988). Because of its early expression and location, which allows direct axonal contact, MAG was for a long time believed to play a key role in transducing the signal that triggers the Schwann cell or oligodendrocyte to wrap the axon with many layers of compact myelin (Salzer et al., 1990; Trapp, 1990). However, in MAGdeficient animals, essentially normal compact myelin is formed (Li et al., 1994; Montag et al., 1994). With time, however, not only myelin degeneration, but also axonal degeneration, occurs in these mice (Fruttiger et al., 1995; Pan et al., 2005), which implies that MAG does indeed interact with the axon and that this inter-

Received May 25, 2007; accepted June 29, 2007

This work was supported by National Institutes of Health (NIH) Grant NS 37060, NIH Specialized Neuroscience Research Programs Grant NS41073, and core facility grants from the NIH Research Centers for Minorities Institute. We thank Melissa Hilaire for her outstanding technical support, Dr. Lloyd Williams for his help with the image analysis, and Dr. Sari Hannila for assistance with this manuscript.

Correspondence should be addressed to Marie T. Filbin, Biology Department, Hunter College, 695 Park Avenue, New York, NY 10021. E-mail: Filbin@genectr.hunter.cuny.edu.

Z. Cao's present address: Wyeth Neuroscience, Wyeth-Ayerst Research, CN 8000, Princeton, NJ 08543.

J. B. Bryson's present address: Columbia University, 701 West 168th Street, HHSC 602, New York, NY 10032.

DOI:10.1523/JNEUROSCI.2404-07.2007

Copyright $\odot 2007$ Society for Neuroscience $\quad$ 0270-6474/07/279146-09\$15.00/0 action is not necessary for the initial formation of myelin, but is for the long-term maintenance of both structures.

In addition to playing an essential role in the maintenance of myelin and myelinated axons, MAG has been shown to be a potent inhibitor of axonal regeneration (McKerracher et al., 1994; Mukhopadhyay et al., 1994). To date, three myelinassociated inhibitors of axonal regeneration have been well-characterized: MAG, NogoA, and oligodendrocyte myelin glycoprotein (OMgp) (Filbin, 2003; Yiu and He, 2006). It is believed that these three inhibitors, along with a number of repulsive guidance cues that play a role during development and which are also expressed in the mature CNS, as well as formation of a glial scar, are major factors preventing spontaneous axonal regeneration after CNS injury (Yiu and He, 2006). Although all are very different in sequence and structure, MAG and OMgp, as well as one of the two inhibitory domains on NogoA, have been shown to interact with the same receptor complex to exert their inhibitory effects (Domeniconi et al., 2002; Liu et al., 2002; Wang et al., 2002a). All three molecules interact with a glycosylphosphatidylinositol-linked protein termed Nogo receptor (NgR1) (Domeniconi et al., 2002; Liu et al., 2002), which in turn interacts with one of two members of the tumor necrosis factor receptor family, the p75 neurotrophin receptor or Troy (Wang et al., 2002b; Wong et al., 2002; Yamashita et al., 2002; Park et al., 2005; Shao et al., 2005). A third member of the receptor complex is a protein called Lingo (Mi et al., 2004). In addition, it has been reported that the gangliosides GD1a and GT1b can act as neuro- 
nal receptors for MAG and that this interaction is necessary for MAG to bring about inhibition (Vyas et al., 2002). More recently, $\mathrm{NgR} 2$, another member of the NgR family of molecules, has been shown to bind MAG, but not Nogo66 or OMgp, with high affinity (Venkatesh et al., 2005). Other components of the $\mathrm{NgR} 2$ receptor complex have yet to be described.

MAG is a sialic acid binding protein, a member of the Siglec family of molecules (sialic acid-binding, immunoglobulin-like lectins), and it preferentially binds the "NeuAc $\alpha 3 \mathrm{Gal} \beta 3 \mathrm{Gal}-$ NAc" glycan structure. Because of these characteristics, MAG can indeed bind the gangliosides GD1a and GT1b (Kelm et al., 1994; Collins et al., 1997; Crocker et al., 1998; Vinson et al., 2001). Previously, however, we showed that arginine 118 (Arg 118), which is present in the first of MAG's five Ig-like domains and is an amino acid conserved in a number of Siglecs, is essential for sialic acid binding (Tang et al., 1997). Surprisingly, although mutant forms of MAG in which Arg 118 was changed to either alanine or aspartate could no longer bind sialic acid, they still inhibited neurite outgrowth as effectively as wild-type MAG (Tang et al., 1997). This indicted that the sialic acid binding ability of MAG is not necessary for inhibition. Consistent with this, we also showed that a truncated, chimeric, soluble form of MAG, consisting of the first three Ig-like domains fused to the Fc portion of human IgG, could bind to neurons in a sialic acid-dependent manner, but did not inhibit neurite outgrowth (Tang et al., 1997). We concluded from these findings that MAG has two recognition sites, a sialic acid binding site in Ig domain 1 and a distinct inhibition site, which is absent from the first three Ig domains.

Here, we show that the inhibition domain on MAG is present in Ig domain 5 (Ig-5) and that various peptides corresponding to amino acid sequences in this domain, but not peptides corresponding to sequences in Ig domain 4, can reverse the inhibition of neurite outgrowth by MAG and myelin in culture. We conclude that the interaction of MAG Ig-5 with the neuron is both necessary and sufficient to bring about inhibition and that sialic acid binding is not needed. In addition, the identification of peptides that block the inhibition by MAG and myelin may be therapeutically beneficial by encouraging axonal regeneration after CNS injury or disease.

\section{Materials and Methods}

Preparation of truncated MAG and MAG-Sn constructs. Two truncated MAG proteins, $\mathrm{MAG}(\mathrm{d} 1-3)$ and $\mathrm{MAG}(\mathrm{d} 3-5)$, and the three chimeric constructs Sn(d1-3)MAG(d4-5), Sn(d1-4)MAG(5) and Sn(d13)MAG(d4)Sn(d5) were synthesized by overlap extension PCR modified from "sticky feet"directed mutagenesis (Clackson and Winter, 1989). The PCR products of chimeric MAG-Sn cDNA fragment were then ligated and transformed into pCR-Script Amp SK(+) plasmid following pCR-Script Amp SK(+) cloning protocol (Stratagene, La Jolla, CA). After sequencing, the chimeric MAG-Sn cDNA was cut with restriction enzyme and subcloned into the expression vector pcDNA3.1, which contains a G418 resistance site.

Expression of MAG and MAG-Sn chimeras by CHO Cells. Chinese hamster ovary $(\mathrm{CHO})$ cells were transfected with $5 \mu \mathrm{g}$ of DNA per $10 \mathrm{~cm}$ plate following the protocol for stable transfection of adherent cells (SuperFect Transfection; Qiagen, Valencia, CA). Media containing transfection complex was removed from the cells by gentle aspiration 4 h posttransfection and cells were washed three to four times with $4 \mathrm{ml}$ of PBS followed by incubation in normal growth medium for $48 \mathrm{~h}$ before changing into G418-selection medium. After 2-3 weeks of selection, the entire population of transfected cells was sorted by fluorescence-activated cell sorting (FACS) for protein expression. Positive cells were diluted and grown as single-cell clones. After 2-3 weeks, clones had expanded and a number of clones were picked, expanded, and screened for expression of
MAG or MAG-Sn chimera by Western blot analysis and cell surface immunofluorescent staining.

Western blot analysis. Cells (80-90\% confluent) were lysed in $0.5 \mathrm{M}$ Tris-HCI, pH 7.5, containing 2\% SDS, $1 \mu \mathrm{g} / \mathrm{ml}$ chymotrypsin, $1 \mu \mathrm{g} / \mathrm{ml}$ pepstatin, and $1 \mathrm{~mm}$ phenylmethylsulfonyl fluoride. The lysate was homogenized by passage through a 23 -gauge syringe. Protein concentration was measured with a Bio-Rad (Hercules, CA) kit before the addition of $\beta$-mercaptoethanol. The lysates were incubated at $95^{\circ} \mathrm{C}$ for $5 \mathrm{~min}$, after which they were subjected to SDS-PAGE (10\%). The proteins were transferred to polyvinylidene difluoride membranes and immunostained with MAG monoclonal antibody (Millipore, Temecula, CA) $(2 \mu \mathrm{g} / \mathrm{ml})$, which recognizes MAG Ig domains 1-3, or B11F7 (Dobersen et al., 1985) (2.6 $\mu \mathrm{g} / \mathrm{ml}$ ), which recognizes MAG Ig domain 4 . For MAG-Sn chimeric expressing cells, a combination of two monoclonal antibodies, 3D6 and SER4 (each at $1 \mu \mathrm{g} / \mathrm{ml}$; gifts from Dr. Paul R. Crocker, University of Dundee, Dundee, UK), which recognize sialoadhesin Ig domains 1 and $2 / 3$, respectively, were used. Incubation was for $1 \mathrm{~h}$ at room temperature. After two washes with PBS-Tween 20, the membranes were incubated with HRP-conjugated anti-mouse IgG (1:5000) at room temperature for $1 \mathrm{~h}$. After an additional three washes with PBS-Tween 20, HRP was visualized with ECL Western blotting reagent.

Immunostaining of MAG and MAG-Sn chimeras expressed by $\mathrm{CHO}$ cells. Cells were grown overnight in chambers of eight-well tissue culture slides coated with poly-L-lysine (Sigma, St. Louis, MO) and fibronectin (Sigma) and fixed with $4 \%$ paraformaldehyde for $15 \mathrm{~min}$ at room temperature. Cultures were then washed with PBS three times and incubated with antibody at $4^{\circ} \mathrm{C}$ overnight. For cells expressing MAG-Sn chimeric protein, two monoclonal antibodies SER4 and 3D6 $(1 \mu \mathrm{g} / \mathrm{ml}$; gifts from Dr. Paul R. Crocker) against sialoadhesin Ig domain $2 / 3$ and domain 1 , respectively, were used together as a primary antibody. For MAG(d1-3) and wild-type MAG-expressing cells, monoclonal antibody 513 was used as primary antibody $(2 \mu \mathrm{g} / \mathrm{ml})$. MAG(d3-5) protein was detected by polyclonal anti-MAG antibody extracellular domain $(4 \mu \mathrm{g} / \mathrm{ml})$ (a gift from Dr. James Salzer, New York University School of Medicine, New York, NY). Oregon green goat anti-mouse IgG was used as the secondary antibody and cells were viewed with a Zeiss (Thornwood, NY) fluorescence microscope.

Sialic acid-dependent binding of human erythrocytes to $\mathrm{CHO}$. Confluent monolayers of $\mathrm{CHO}$ expressing wild-type MAG, mutated MAG, or control cells were established over a $24 \mathrm{~h}$ period in individual chambers of an eight-well tissue culture slide (Lab-Tek, Naperville, IL). Monolayers were treated for $1 \mathrm{~h}$ with $200 \mathrm{mU} / \mathrm{ml}$ Vibrio cholerae at $37^{\circ} \mathrm{C}$ and washed twice. The medium was changed to DMEM and $1 \times 10^{7}$ human erythrocytes in HEPES-DMEM were added and incubated for $1 \mathrm{~h}$ at $37^{\circ} \mathrm{C}$. Unbound erythrocytes were washed off and cells were examined and photographed under a phase-contrast microscope and photographed.

Neurite outgrowth on transfected $\mathrm{CHO}$ cells. Confluent monolayers of $\mathrm{CHO}$ cells expressing wild-type MAG, truncated MAG, MAG-Sn chimeras, or control $\mathrm{CHO}$ cells were established over a $24 \mathrm{~h}$ period in individual chambers of an eight-well tissue culture slide (Lab-Tek). Cocultures were established as described previously (Doherty et al.,1990; Mukhopadhyay et al., 1994) by adding $5 \times 10^{4} \mathrm{P} 5$ cerebellar neurons in Sato media to the $\mathrm{CHO}$ cell monolayers. MAG or Sn peptides were included at $50 \mu \mathrm{g} / \mathrm{ml}$ as indicated. After $16-18 \mathrm{~h}$, the cocultures were fixed for 30 min with $4 \%$ paraformaldehyde, and permeabilized with ice-cold methanol for $2 \mathrm{~min}$. The cells were then blocked for 20 min with DMEM containing 10\% FCS and incubated for $2 \mathrm{~h}$ with a rabbit polyclonal antibody against growthassociated protein 43 (GAP43; 1:4000; a gift from R. Curtis and G. Wilkins, Imperial College, London, UK). Cells were washed three times with $2 \%$ PBS-BSA (2\%) and then incubated for $30 \mathrm{~min}$ at room temperature with a biotinylated donkey anti-rabbit Ig (1:300; Amersham Biosciences, Arlington Heights, IL), washed three times, and incubated with streptavidin-conjugated Texas red (1:300; Amersham Biosciences) for 45 min. After three more washes, the slides were mounted in Permafluor (Baxter Healthcare Miami, FL) and viewed with a Zeiss fluorescent microscope. The length of the longest neurite for each GAP43-positive neuron was determined for the first 180-200 neurons encountered when scanning the slide in a systematic manner using the Uncor image-analysis program. 
A

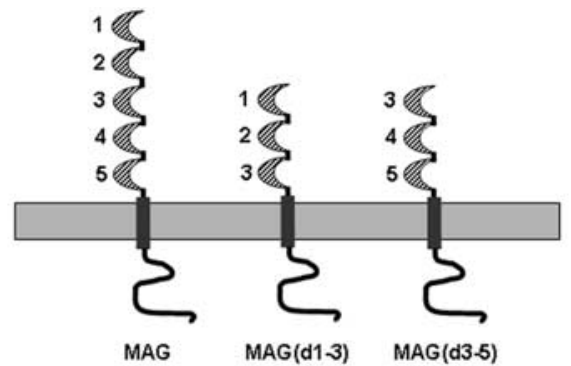

B

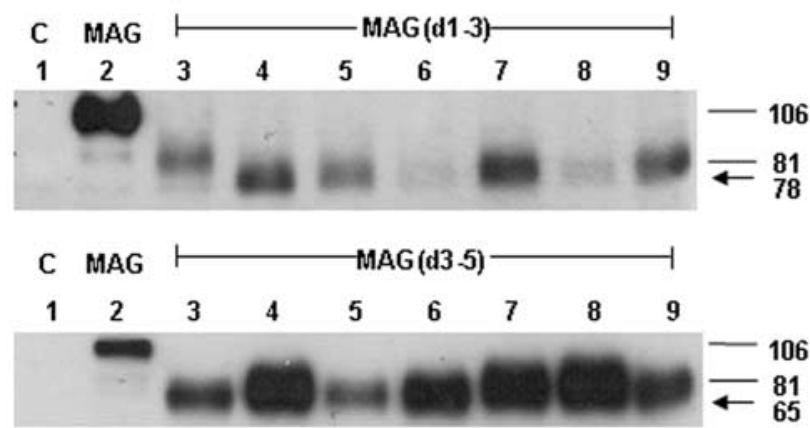

C
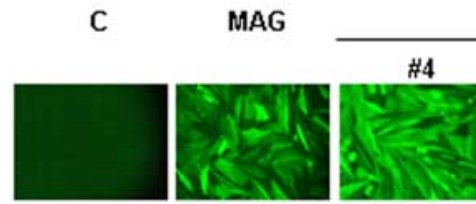

MAG(d1 3)

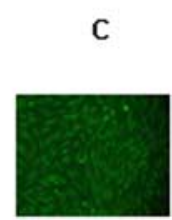

MAG

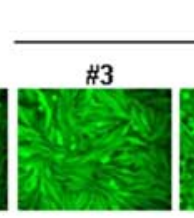

MAG (d3 -5)
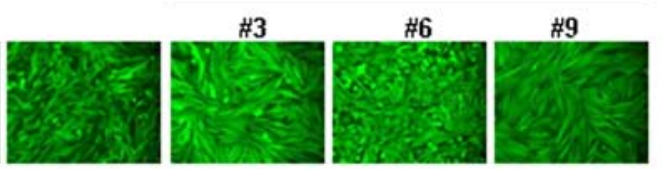

D
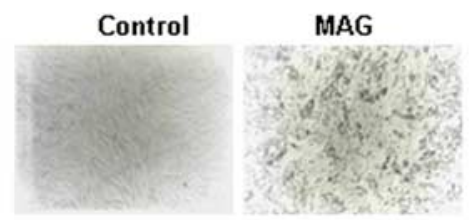

\#4

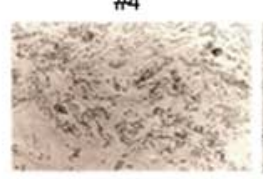

\#3

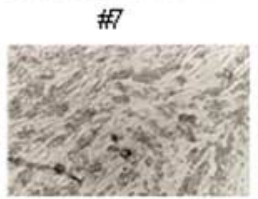

$\$ 6$
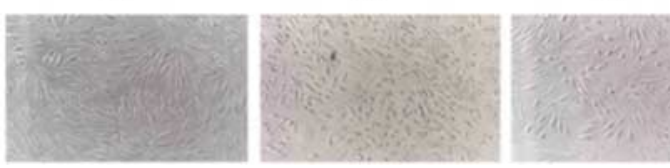

\#9
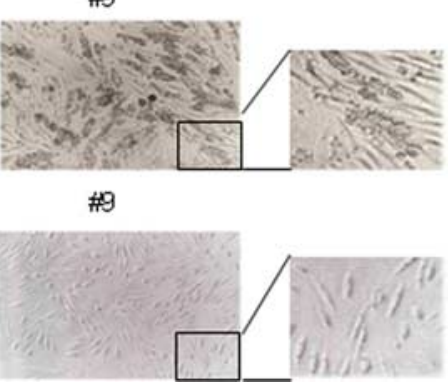

Figure 1. Characterization of expression of truncated MAG by $\mathrm{CHO}$ cells. $A$, Schematic diagram showing the predicted MAG proteins to be expressed. MAG (full-length MAG), MAG(d1-3) (MAG Ig domains 1, 2, and 3) and MAG(d3-5) (MAG Ig domains 3, 4, and 5) each fused to the transmembrane and cytoplasmic domains of wild-type MAG. $\boldsymbol{B}$, Western blot analysis of transfected CHO cells expressing MAG. CHO cells were transfected with constructs containing CDNA for full-length MAG (MAG), MAG(d1-3), MAG(3-5) or plasmids without MAG CDNA. Cells were FACS sorted for expressors and these were then single cell cloned. Lanes 3-9 in the top and bottom panels refer to individual clones of $M A G(d 1-3)$ and $M A G(d 3-5)$, respectively. Top panel Western blot was incubated with MAG 513 monoclonal antibody and the bottom panel was incubated with MAG B11F7 monoclonal antibody. Arrows refer to the truncated MAG proteins. Ten micrograms of total protein was loaded per well. C, Control. C, Surface expression of MAG by transfected $\mathrm{CHO}$ cells. Three clonal lines each of $\mathrm{CHO}$ cells expressing MAG(d1-3) (top) and MAG(d3-5) (bottom) were
Myelin preparation. Myelin was purified from rat CNS white matter following the Norton protocol (Norton and Poduslo, 1973). After the final hypotonic shock, the membranes were centrifuged and resuspended in $10 \mathrm{mM}$ HEPES. The protein concentration of the preparation was determined and used immediately as a substrate in the neurite outgrowth assay.

Neurite outgrowth on immobilized myelin. The wells of an eight-chamber tissue culture slides (Lab-Tek) were first coated with 16.6 $\mu \mathrm{g} / \mathrm{ml}$ poly-L-lysine at room temperature for $1 \mathrm{~h}$. Rat CNS myelin at $0.5-2 \mu \mathrm{g}$ of total protein/well was dried overnight onto the coated wells and used as a substrate (Shen et al., 1998). A total of $2 \times 10^{4}$ P5 cerebellar neurons suspended in Sato media with 2\% FBS were plated into each well and incubated at $37^{\circ} \mathrm{C}$ for $24 \mathrm{~h}$. As a control, poly-L-lysine was used as a substrate. Fixation, immunostaining, and measurement of neurite outgrowth were as described above for neurite outgrowth on $\mathrm{CHO}$ cells.

\section{Results}

The inhibition site on MAG is within Ig domains 3, 4, and 5

Previously, we established that sialic acid binding by MAG is not necessary for it to inhibit neurite outgrowth (Tang et al., 1997). Furthermore, we showed that a soluble, truncated chimeric form of MAG consisting of MAG Ig domains 1-3 fused to the Fc region of human IgG [MAG(d13)-Fc] and bound to neurons in a sialic acid-dependent manner but, did not inhibit neurite outgrowth (Tang et al., 1997). We therefore proposed that inhibition requires the presence of Ig domains 4 and 5 and perhaps that these two domains are sufficient, without Ig domains $1-3$, to inhibit neurite outgrowth. However, it is possible that soluble, truncated forms of MAG interact differently with the neuronal receptor than when it is membrane bound via its transmembrane and cytoplasmic domains. Therefore, we wanted to determine (1) whether MAG(d1-3), when

chosen and grown as monolayer. Unfixed cells were incubated with either MAG 513 monoclonal antibody (top) or with MAG B11F7 monoclonal antibody (bottom) before being fixed and incubated with fluorescent-conjugated secondary antibody. Numbers refer to the lanes of the clones in $\boldsymbol{B}$. $\boldsymbol{D}$, Sialic acid binding of MAG-expressing $\mathrm{CHO}$ cells. Monolayers of control, full-length (MAG), or truncated MAG-expressing $\mathrm{CHO}$ cells were treated with neuraminidase to remove the cisbinding sialic acid residues before being incubated with native human erythrocytes. The three single-cell clones of each truncated MAG as described in $\boldsymbol{B}$ and $\boldsymbol{C}$ were used. Binding of cell surface proteins to sialic acid-containing glycoconjugates can be assessed by the formation of "rosette"-like erythrocytes clusters on top of the monolayers. Results reveal erythrocyte binding to full-length MAG- and MAG(d1-3)-, but not to MAG(d3-5)-expressing $\mathrm{CHO}$ cells, clearly revealed by the magnification of \#9 MAG (d3-5), but not \#9 MAG(d3-5). 
expressed as a transmembrane protein, behaves in the same way as soluble MAG(d1-3)-Fc (i.e., does not inhibit neurite growth), and (2) whether Ig domains 4 and 5 alone are sufficient to inhibit neurite outgrowth. To do this, we made the truncated forms of transmembrane MAG shown in Figure $1 A$. These were transfected into $\mathrm{CHO}$ cells, single-cell cloned for expressors, and characterized, before carrying out the neurite outgrowth assay. Unfortunately, we had difficulty expressing only Ig domains 4-5 in $\mathrm{CHO}$ cells, so instead we expressed Ig domains 3, 4, and 5 [MAG(d3-5)].

After single cell cloning, a number of individual clones were expanded and screened for expression of the various MAG constructs. Although we had already created a number of MAGexpressing $\mathrm{CHO}$ cell lines, we created new lines expressing fulllength MAG, to ensure that all the lines used for comparison underwent the same treatments. Figure $1 B$ shows Western blots of transfected cell lysates immunostained for MAG and, as can be seen, there is considerable variation in the level of expression of the various proteins from clone to clone. For each construct, we choose three MAG-expressing cell lines that were expressing comparable amounts of the protein. For MAG(d1-3), we chose the clones represented in lanes 4, 7, and 9, and for MAG(d3-5), we chose clones represented in lanes 3, 6, and 9. Controls on these westerns were $\mathrm{CHO}$ cells transfected with full-length MAG or transfected with control plasmids.

The eight chosen clonal lines [three $\mathrm{MAG}(\mathrm{d} 1-3)$, three MAG(d3-5), and two full-length MAG] were plated and immunostained to assess surface expression of the various MAG proteins. A monoclonal antibody that recognizes native MAG and that has its epitope in MAG Ig domain 1 was used to stain MAG(d1-3)-expressing cells (Meyer-Franke et al., 1995), and a polyclonal antibody raised to the entire extracellular domain of MAG was used to stain MAG(d3-5)-expressing cells (Quarles et al., 1981). To ensure that only surface MAG was detected, the primary antibodies were incubated with the cells before they were fixed and stained. As can been seen in Figure $1 C$, there is comparable expression of the various MAG proteins at the cell surface for all of the cell lines, except for the control transfected cells, which do not express MAG.

To determine whether the MAG(d1-3)-expressing cell lines had retained their sialic acid-binding capabilities, we assessed their ability to bind human erythrocytes, which express an abundance of well characterized sialoglycans and which we have used before to demonstrate the sialic acid binding of MAG (Kelm et al., 1994). All the cell lines were treated with sialidase before incubation with the erythrocytes to eliminate cis-sialic acid interactions of the MAG proteins. For all MAG(d1-3)- and full-length MAGexpressing lines, the human erythrocytes bound in characteristic "rosette"-like clusters (Fig. 1D). This binding was lost completely if the erythrocytes were treated with sialidase before incubation with $\mathrm{CHO}$ cells, confirming that binding is indeed sialic acid dependent (data not shown). There was no binding of erythrocytes to the MAG(d3-5)-expressing cells or to the control transfected cells (Fig. 1D). This is consistent with location of the sialic acid binding site to MAG Ig domain 1 .

To assess whether these various forms of MAG could inhibit neurite outgrowth, we plated the various cell lines and allowed them to form monolayers. P5 cerebellar neurons were then plated on the monolayers, allowed to extend neurites overnight, then fixed and stained for GAP43, and finally neurite length was measured. Figure 2 shows that, as we have reported before, full-length MAG potently inhibits neurite outgrowth when compared with neurite length on control transfected cells that do not express
A

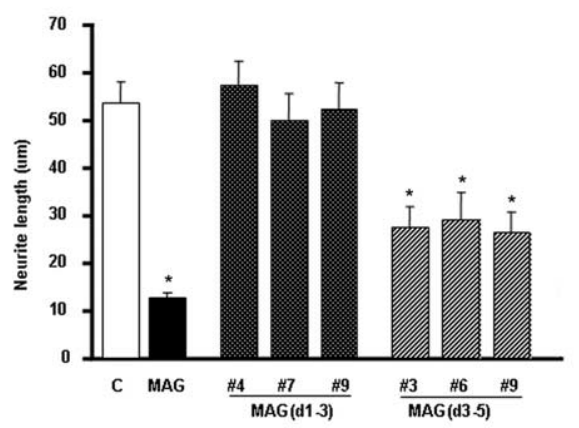

B
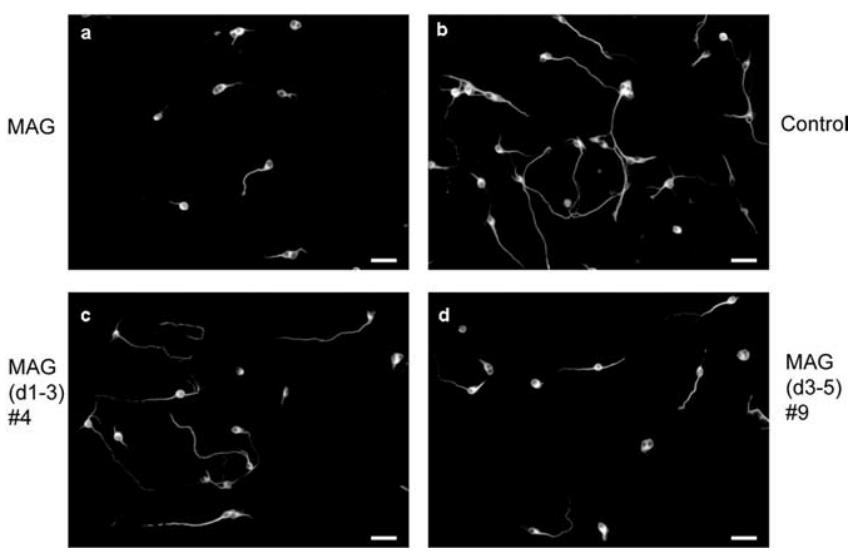

Figure 2. The effect of MAG(d1-3) and MAG(d3-5) on neurite outgrowth from cerebellar neurons. $A$, Dissociated cerebellar neurons from P5 rats were cultured for $18 \mathrm{~h}$ on confluent monolayers of control (C), full-length MAG-expressing cells (MAG), MAG(d1-3)- or MAG(d35)-expressing $\mathrm{CHO}$ cells (numbers indicate different single cell as described in Fig. 1). The cocultures were fixed and stained for GAP43 and the longest neurite of each GAP43 positive neuron was measured. Results show the mean length of the longest neurite per cell ( \pm SEM) for $150-$ 200 neurons. * Statistically different from neurite length on control cells not expressing MAG; $p \leq 0.005$, paired Student's $t$ test. $\boldsymbol{B}$, Representative images of neurons grown on the various monolayers of $\mathrm{CHO}$ cells as indicated. Scale bars, $20 \mu \mathrm{m}$.

MAG. Consistent with our previous findings demonstrating that sialic acid binding alone by MAG is insufficient to inhibit neurite outgrowth, none of the three cell lines expressing MAG(d1-3) inhibited neurite outgrowth. Growth on these cells was equivalent to that observed on the control transfected cells (Fig. 2). In sharp contrast, the cells expressing MAG(d3-5) effectively and significantly inhibited neurite outgrowth. The inhibition, however, is not quite as strong as that seen with full-length MAG. This suggests that, although sialic acid binding of MAG to neurons is neither sufficient nor necessary for MAG to inhibit neurite outgrowth, it appears to potentiate the effect. These results also confirm that transmembrane MAG(d1-3), like soluble MAG(d1-3), cannot inhibit neurite outgrowth, that inhibition by MAG does not requite Ig domains 1 and 2, and that the inhibition site is contained within Ig domains 3-5.

\section{The inhibition site on MAG is present within Ig domain 5}

To determine whether the inhibitory region on MAG could be mapped to any single Ig domain, we made chimeric molecules in which various MAG-Ig domains were replaced with the equivalent Ig domains from another Siglec family member, sialoadhesin (Siglec 1). Arg 118 in Ig domain 1 is crucial for sialic acid binding of MAG, and this residue is conserved in Sn as Arg 97 (Vinson et al., 1996). Like MAG, Sn preferentially binds GT1b and GD1a, but unlike MAG, Sn does not inhibit neurite outgrowth. (Kelm et 
A

MAG

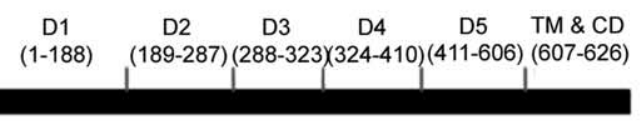

Sn(d1-3)MAG(d4-5)

$\mathrm{Sn}(\mathrm{d} 1-3) \mathrm{MAG}(\mathrm{d} 4) \mathrm{Sn}(\mathrm{d} 5)$

$\mathrm{Sn}(\mathrm{d} 1-4) \mathrm{MAG}(\mathrm{d} 5)$

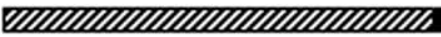
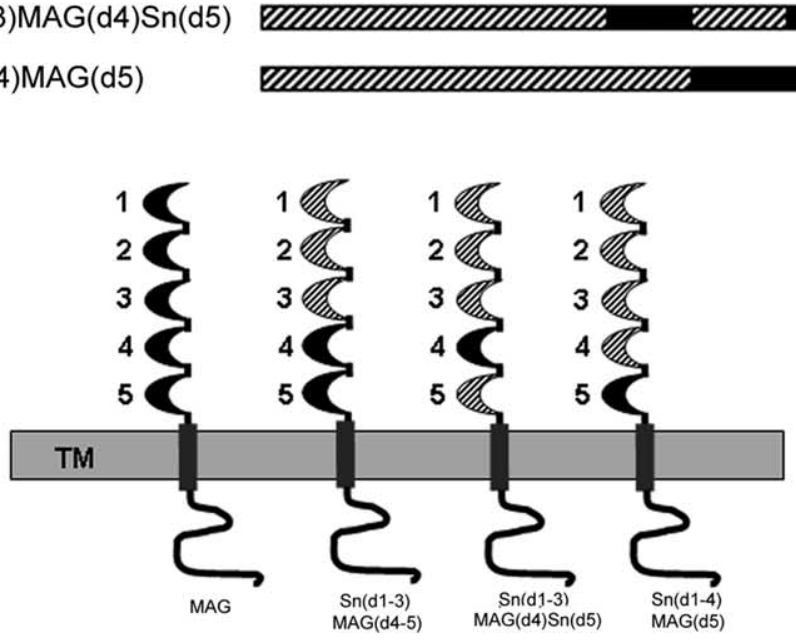

B

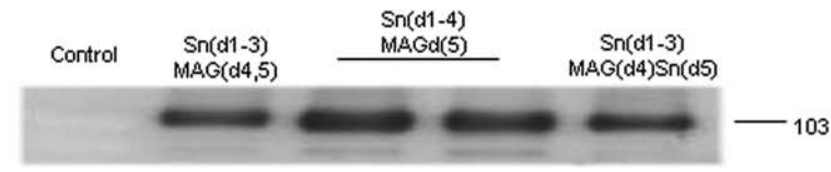

C

Control MAG(d1-5)
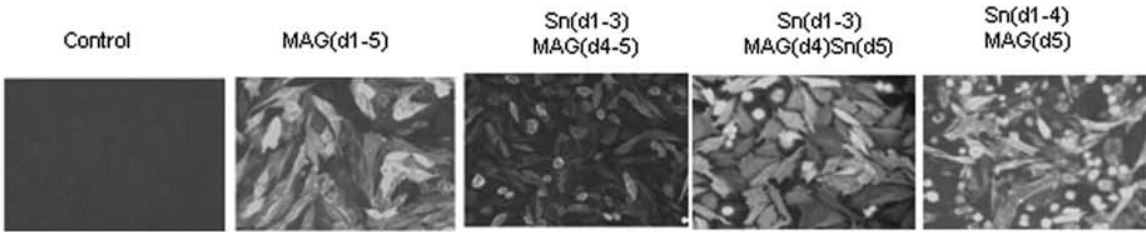

D

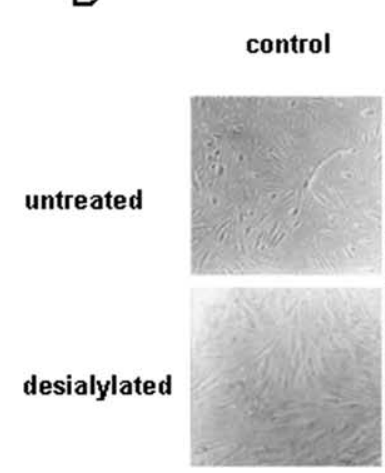

MAG

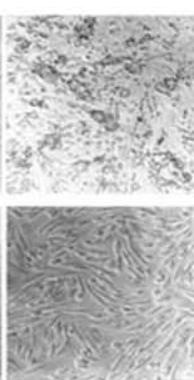

\section{Sn(d1-3)} MAG(d4-5)
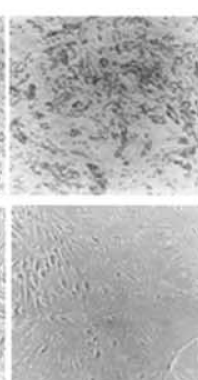

Sn(d1-3) MAG (d4 -5) $\operatorname{Sn}(d 5)$

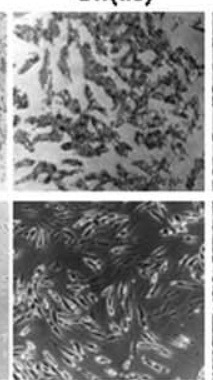

Sn(d1-4) MAG(d5)

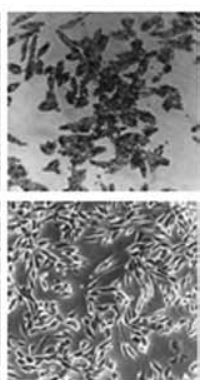

Figure 3. Characterization of expression of truncated MAG by $\mathrm{CHO}$ cells. $A$, Schematic diagram showing the predicted MAG-Sn chimeric proteins to be expressed. Chimeric constructs consisting of the CDNAs for the various Ig domains of MAG (black) and $\mathrm{Sn}$ (hatched) were created as indicated. All constructs contained wild-type MAG transmembrane and cytoplasmic sequences. $\boldsymbol{B}$, Western blot analysis of transfected $\mathrm{CHO}$ cells expressing MAG-Sn chimeric proteins. CHO cells were transfected with constructs containing CDNA for the chimeric proteins as indicated. Cells were FACS sorted for expressors and these were then single-cell cloned. The Western blot was incubated with a combination of two $\mathrm{Sn}$ monoclonal antibodies. Ten micrograms of total protein were loaded per well. C, Surface expression of MAG-Sn chimeric proteins by transfected $\mathrm{CHO}$ cells. Individual clones were grown as a monolayer and unfixed cells expressing the chimeric proteins were incubated with a combination of two Sn monoclonal antibodies and cells expressing wild-type MAG were incubated with MAG 513 monoclonal antibody before being fixed and al., 1994). By using these chimeric molecules, we retain the sialic acid-binding capabilities and so can map the inhibitory domain more confidently. The chimeric molecules are described in Figure $3 A$. Consist with constructs in which the cDNA sequences of MAG Ig domains 1-3 are replaced with Sn Ig domains 1-3 [ $\mathrm{Sn}(\mathrm{d} 1-$ 3)MAG(d4,5)], MAG Ig domains 1-3 and 5 are replaced with $\mathrm{Sn}$ domains $1-3$ and 5 [ $\mathrm{Sn}(\mathrm{d} 1-3)$ MAG(d4)Sn(d5)], and MAG Ig domains 1-4 are replaced with $S n$ domains 1-4, respectively [Sn(d1-4)MAG(d5)].

The constructs were transfected into $\mathrm{CHO}$ cells, single-cell cloned, and screened for expression of the chimeric proteins using either $\mathrm{Sn}$ antibodies or MAG antibodies. Figure $3 B$ shows a Western blot of lysates from a number of different clones. Cell lines expressing approximately equivalent amounts of MAG-Sn protein were selected for additional analysis. The cell lines were immunostained and Figure $3 C$ shows that for all the cell lines chosen, the chimeric proteins are reaching the cell surface. Their sialic acid-binding capability was assessed using the human erythrocyte binding assay. Figure $3 D$ shows that all the clones bound the human erythrocytes in a rosette formation, and this binding was lost if the erythrocytes were desialyated before incubation with the CHO cell lines. There was no erythrocyte binding to control transfected $\mathrm{CHO}$ cells.

To assess which of the chimeric proteins inhibited neurite outgrowth, the various $\mathrm{CHO}$ cell lines were grown as monolayers and P5 cerebellar neurons were plated on them. After overnight growth, the cocultures were fixed, stained for GAP43, and neurite length was measured. Figure 4 shows that, as before, full-length MAG strongly inhibits neurite outgrowth. A similar degree of inhibition was exerted by the $\mathrm{CHO}$ cells expressing $\mathrm{Sn}(\mathrm{d} 1-$ 3)MAG(d4,5) or $\mathrm{Sn}(\mathrm{d} 1-4) \mathrm{MAG}(\mathrm{d} 5)$, but not by $\mathrm{Sn}(\mathrm{d} 1-3) \mathrm{MAG}(\mathrm{d} 4) \mathrm{Sn}(\mathrm{d} 5)$, which did not inhibit neurite outgrowth at all; on

$\leftarrow$

incubated with fluorescent-conjugated secondary antibody. D, Sialic acid binding of MAG-Sn-expressing CHO cells. Monolayers of control, full-length (MAG), or MAG-Sn-expressing CHO cells were treated with neuraminidase to remove the cis-binding sialic acid residues before being incubated with native human erythrocytes. Binding of cell surface proteins to sialic acid-containing glycoconjugates can be assessed by the formation of "rosette"-like erythrocytes clusters on top of the monolayers. Results reveal erythrocyte binding to all MAG and MAG-Sn expressing CHO cells (top). Binding is lost if the erythrocytes are pretreated with neuraminidase (bottom), demonstrating sialic acid dependency. 


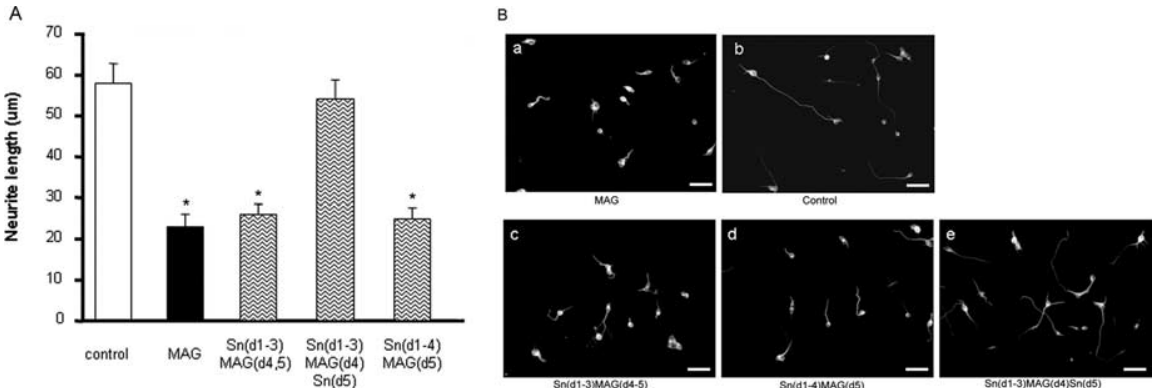

Figure 4. The effect of MAG-Sn chimeric proteins on neurite outgrowth from cerebellar neurons. $\boldsymbol{A}$, Dissociated cerebellar neurons from $\mathrm{P} 5$ rats were cultured for $18 \mathrm{~h}$ on confluent monolayers of control (white bar), full-length MAG- (black bar) or the MAG-Sn- (stippled bars) expressing CHO cells as indicated. The cocultures were fixed and stained for GAP43, and the longest neurite of each GAP43-positive neuron was measured. Results show the mean length of the longest neurite per cell ( \pm SEM) for $150-200$ neurons. *Statistically significantly different from neurite length on control cells not expressing MAG; $p \leq 0.003$, paired Student's $t$ test. $\boldsymbol{B}$, Representative images of neurons grown on the various monolayers of $\mathrm{CH} 0$ cells as indicated. Scale bars, 20 $\mu \mathrm{m}$.

those cells, growth was the same as on the control CHO cells not expressing any form of MAG or Sn (Fig. 4). These results establish that for inhibition to occur, MAG Ig-5 must be present and that its presence alone within the chimeric molecule is sufficient to bring about inhibition. They also demonstrate that MAG Ig-4 is not required for inhibition.

\section{Peptides corresponding to amino acid sequences in MAG Ig-} 5 , but not Ig-4, block inhibition by MAG and myelin

To determine whether peptide sequences corresponding to sequences in MAG Ig-5 could block inhibition of neurite growth, we synthesized the peptides described in Figure $5 A$. They represent overlapping linear sequences spanning MAG Ig-4, the predicted intervening sequence, and MAG Ig-5. Consistent with our findings that the inhibitory region is carried exclusively by MAG Ig-5, only peptides corresponding to sequences in this domain were able to block inhibition by membrane-bound MAG proteins (Fig. 5B) and immobilized CNS myelin (Fig. 5C). Peptides corresponding to MAG Ig-4 or the predicted intervening sequence had no effect on inhibition. The same was true for a peptide corresponding to a sequence in Ig domain 5 of Sn. However, the peptides that did overcome the inhibition of MAG or myelin did so only at very high concentrations ( $50 \mu \mathrm{g} / \mathrm{ml})$, suggesting that they bind only with low affinity to the receptor to block MAG's interaction with it. None of the peptides had any effect on neurite outgrowth from neurons growing on control $\mathrm{CHO}$ cells not expressing MAG (data not shown).

\section{Discussion}

Although MAG binds sialic acid with high affinity and in specific linkages, we reported previously that sialic acid binding by MAG is neither necessary nor sufficient for it to mediate inhibition (Tang et al., 1997). We proposed that MAG interacted with neurons via two sites: a sialic acid binding site requiring Arg 118 in Ig domain 1 and an inhibitory site that required the presence of, at least, MAG Ig domains 4 and 5. Here, we confirm our prediction and map the inhibition site on MAG to within Ig domain 5. This was achieved by systematically substituting the Ig domains of MAG with those of another member of the Siglec family of molecules, sialoadhesin, which recognizes sialic acid in the same linkage as does MAG (Kelm et al., 1994, 1996; Crocker et al., 1998). In this way we were able to retain the sialic acid-binding capabilities of the chimeric molecule as well as 5-Ig domains, typical of fulllength MAG. We found that only when Ig domain 5 of MAG was present in the chimeric molecule did inhibition of neurite outgrowth occur. In fact, $\mathrm{Sn}(1-4)-\mathrm{MAG}(\mathrm{d} 5)$ was as effective in inhibiting neurite outgrowth as wild-type MAG. Furthermore, consistent with the inhibition site being within MAG Ig domain 5, only peptides corresponding to sequences in this domain, and not to sequences within MAG Ig domain 4 or sialoadhesin Ig domain 5, were able to block inhibition by MAG and myelin.

Identification of distinct inhibitory and sialic acid binding sites on MAG is consistent with our working hypothesis and confirms our suggestion that the sialicbinding capabilities of MAG, including binding to gangliosides, is neither necessary nor sufficient to bring about inhibition. However, because inhibition by MAG is slightly, but significantly and consistently, attenuated in the absence of sialic acid binding, sialic acid binding may act to potentiate inhibition by MAG. This is most likely brought about by ganglioside binding promoting a stable clustering of the MAG-NgR:Lingo:p75 receptor-ligand complex. Several lines of evidence support this model. It has been reported that gangliosides promote the coprecipitation of MAG with p75 (Yamashita et al., 2002). Moreover, it has also been shown by a number of groups that clustering gangliosides on neurons, by either chemical cross-linking or with IgE antibodies, is sufficient to bring about inhibition even in the absence of MAG (Vinson et al., 2001; Vyas et al., 2002). These findings indicate that inhibition can be initiated by artificially promoting cisinteractions of the receptor complex, in the absence of ligand. Furthermore, we showed previously that if sialic acid residues are removed from neurons with the enzyme, sialidase, inhibition of neurite outgrowth by MAG is attenuated, but never abolished (Tang et al., 1997). This is also consistent with gangliosides potentiating, but not being necessary for inhibition by MAG. Our conclusion is that gangliosides increase the clustering of the receptor-ligand complexes, most likely as others have reported, in lipid rafts (Vinson et al., 2003; Marta et al., 2004). In addition, because the binding of MAG to NgR2 is reported to be sialic acid-dependent, it is possible that the inhibition by MAG is also potentiated through this interaction (Venkatesh et al., 2005). It remains to be determined, however, if NgR2 itself carries the sialic acid residues that are responsible for direct MAG binding.

Although peptides corresponding to sequences in Ig domain 5 of MAG are effective in blocking inhibition by MAG and myelin in culture, they had no effect on regeneration of sensory axons in vivo when delivered intrathecally (data not shown) (delivery of 50 $\mu \mathrm{g} / \mathrm{ml}$ peptide intrathecally for 2 weeks, commencing at the same time that the dorsal column lesion is inflicted). This could be attributable to a number of reasons. First, high concentrations of the peptides are necessary to block inhibition by MAG and myelin even in culture, which is indicative of low-affinity binding. It is extremely difficult to deliver and sustain high intrathecal concentrations of agents for prolonged periods of time. The low-affinity binding of the peptides is most likely because they represent linear sequences in MAG Ig domain 5 and it is unlikely that the inhibition site is carried by a linear sequence of amino acids. Design of a high-affinity small peptide that blocks MAG-receptor interaction will have to wait until the crystal structure of MAG Ig domain 5 is solved. Second, although three of the myelin- 

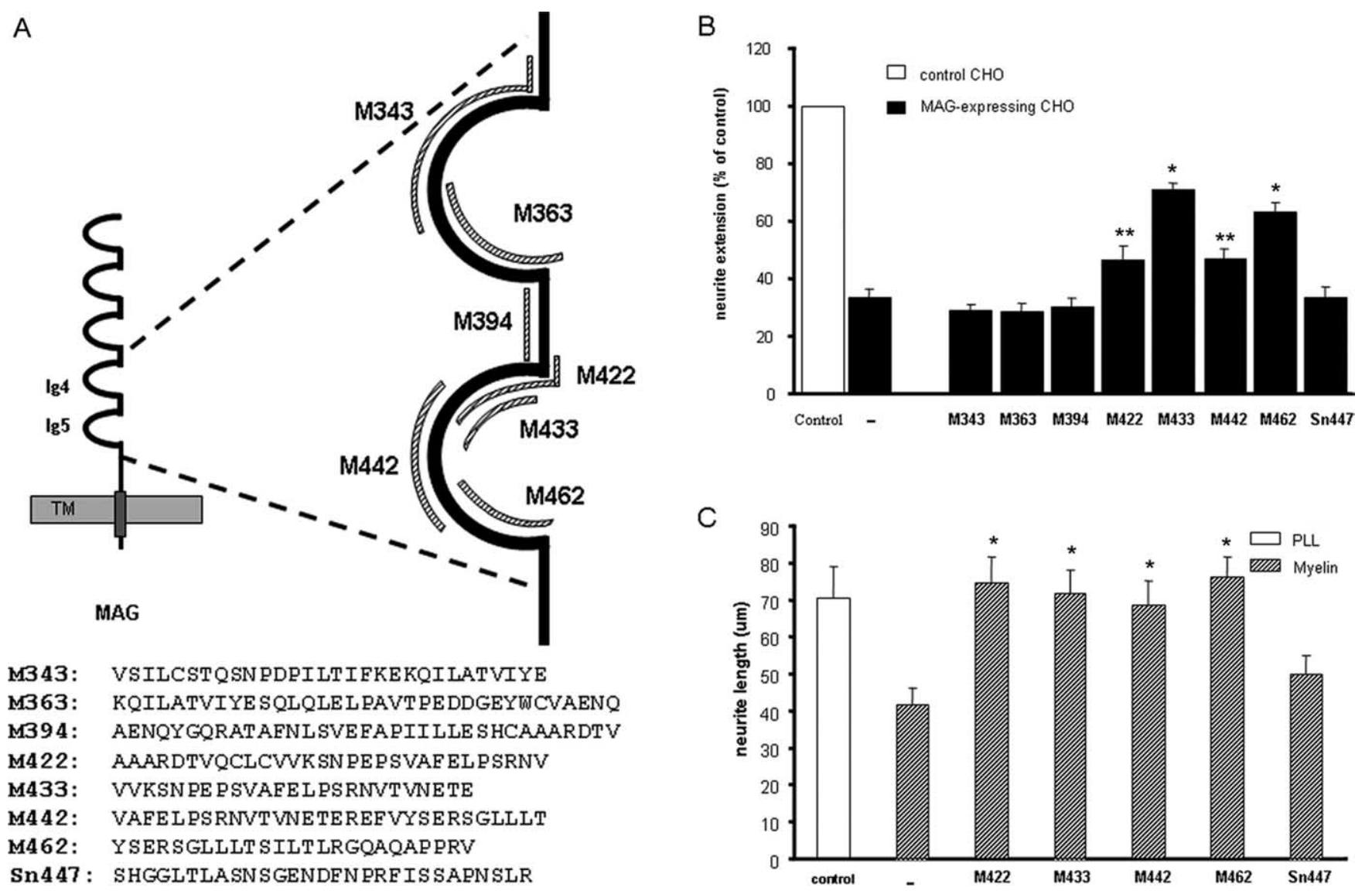

Figure 5. Block of inhibition by MAG and myelin by peptides corresponding to Ig domains 5. A, Location in MAG of the peptides synthesized (top) and the sequence of those peptides (bottom). $\boldsymbol{B}, \boldsymbol{C}$, The effect of the peptides on inhibition by MAG $(\boldsymbol{B})$ and myelin (C). Dissociated cerebellar neurons from P5 rats were cultured with and without peptide (50 $\mu \mathrm{g} / \mathrm{ml})$ for $18 \mathrm{~h}$ on confluent monolayers of control (white bar) or full-length MAG-expressing $\mathbf{C H O}$ (black bar) cells $(\boldsymbol{B})$, or on immobilized myelin (stripped bars) or poly--lysine (white bar) (C). The cultures were fixed and stained for GAP43, and the longest neurite of each GAP43-positive neuron was measured. Results show the mean length of the longest neurite per cell ( \pm SEM) for 150-200 neurons. Statistically significantly different from neurite length on MAG-expressing cells; ${ }^{*} p \leq 0.001 ;{ }^{* *} p \leq 0.01$, paired Student's $t$ test.

associated inhibitors described to date interact with NgR1 to effect inhibition of axonal regeneration, there are other receptorligand interactions that contribute to the block of growth (Filbin, 2003; Yiu and He, 2006). Therefore, it is probable that there is redundancy in inhibitors and that achieving regeneration in vivo may be more effective when these other interactions are blocked in conjunction with MAG and myelin.

It is somewhat surprising that the inhibitory domain of MAG maps to the Ig domain closest to the membrane, Ig-5, and not to one at the $\mathrm{N}$-terminus, which would be predicted to be in a better position to interact with the neuron. However, because the sialic acid binding domain of MAG is carried on Ig-1, and because sialic acid binding by MAG augments inhibition, a structure can be envisaged in which the extracellular domain of MAG forms a hairpin loop. In this way, Ig-1 and Ig-5 would be aligned, enabling both to interact with components of the neuronal membrane. Indeed, such a folded structure was suggested previously for MAG based on studies from electron microscopy analysis of rotary-shadowed soluble MAG molecules (Fahrig et al., 1993). Furthermore, a precedent for such folding of proteins with multiple Ig domains has already been set based on the crystal structure of Tag-1 and hemolin (Su et al., 1998; Freigang et al., 2000).

Our conclusion that sialic acid binding and, hence, gangliosides are neither necessary nor sufficient for MAG to inhibit neurite outgrowth is in sharp contrast to what others have reported.
A number of groups have reported that inhibition by MAG and myelin can be blocked completely by sugars that resemble the structure of the terminal sugars on gangliosides, by ganglioside antibodies, and by treatment with sialidase, which removes sialic acid (Vinson et al., 2001; Vyas et al., 2002, 2005; Yang et al., 2006). In addition, they have reported that inhibition by MAG and myelin is attenuated when neurons from animals that fail to synthesize complex gangliosides, such as GT1b and GD1a, are used (Vyas et al., 2002). The effect of sugars and antibodies on inhibition by MAG could be a consequence of steric hindrance. That is to say, although not essential for inhibition, it is highly probable that gangliosides are present in the receptor-ligand complex. Hence, if a large molecule, such as a sugar or antibody, binds either to the gangliosides themselves or to the sialic acid binding site on MAG, interactions that are required for inhibition would likely be disrupted and inhibition would be blocked. Alternatively, differences in how inhibition by MAG and myelin is assessed could account for the discrepancies between the different groups. The majority of our studies are performed either with the ligand, MAG, expressed on the surface of live cells or with MAGFc, a soluble, chimeric, dimeric form of MAG. After binding, both these forms of MAG still permit movement of the receptor within the neuronal membrane. In studies reporting an absolute requirement for sialic acid/gangliosides binding for inhibition by MAG, immobilized MAG was used (Vinson et al., 2001; Vyas et 
al., 2002, 2005). The apparent difference in requirements for gangliosides may be a reflection of whether the receptor can move within its own membrane after ligand binding or if, after binding, it becomes fixed to the ligand's position. The latter situation is of course less physiological. The same differences in requirements for gangliosides have been reported when myelin is used as a substrate. Again, however, there are differences in preparation: we plate neurons directly onto myelin membranes whereas others extract the protein with detergent before immobilizing them and plating the neurons (Vyas et al., 2002, 2005).

Although ganglioside-MAG interaction does not appear to be essential for inhibition of neurite outgrowth, it is crucial for longterm maintenance of axon-myelin interactions in vivo. This is because MAG-deficient mice and mice that cannot synthesize complex gangliosides such as the MAG-binding partners GT1b and GDla have almost identical phenotypes (Fruttiger et al., 1995; Sheikh et al., 1999). In both lines of mutant mice, myelin formation is essentially normal and there is no functional deficit. With age, however, both lines of mice exhibit quantitively similar demyelination and axonal degeneration in both the CNS and PNS, and similar motor behavioral deficits. In double-null mice, morphological changes were similar to those reported for either null, and motor deficits in these mice were only modestly more impaired (Pan et al., 2005). These results strongly suggest that MAG-ganglioside interaction is crucial for the maintenance of axon-myelin stability.

In conclusion, we have mapped the inhibition site on MAG to Ig domain 5 and strengthened our suggestion that sialic acid binding is not required for this effect. The challenge is now to precisely map the inhibition site within MAG Ig-5 so that peptides that bind to this site with high affinity and which will block inhibition, can be rationally designed.

\section{References}

Clackson T, Winter G (1989) "Sticky feet"-directed mutagenesis and its application to swapping antibody domains. Nucleic Acids Res 17:10163-10170.

Collins BE, Yang LJ, Mukhopadhyay G, Filbin MT, Kiso M, Hasegawa A, Schnaar RL (1997) Sialic acid specificity of myelin-associated glycoprotein binding. J Biol Chem 272:1248-1255.

Crocker PR, Clark EA, Filbin M, Gordon S, Jones Y, Kehrl JH, Kelm S, Le Douarin N, Powell L, Roder J, Schnaar RL, Sgroi DC, Stamenkovic K, Schauer R, Schachner M, van den Berg TK, van der Merwe PA, Watt SM, Varki A (1998) Siglecs: a family of sialic-acid binding lectins [letter]. Glycobiology 8:v.

Dobersen MJ, Hammer JA, Noronha AB, MacIntosh TD, Trapp BD, Brady RO, Quarles RH (1985) Generation and characterization of mouse monoclonal antibodies to the myelin-associated glycoprotein (MAG). Neurochem Res 10:499-513.

Doherty P, Fruns M, Seaton P, Dickson G, Barton CH, Sears TA, Walsh FS (1990) A threshold effect of the major isoforms of NCAM on neurite outgrowth. Nature 343:464-466.

Domeniconi M, Cao Z, Spencer T, Sivasankaran R, Wang RC, Nikulina E, Kimura N, Cai H, Deng K, Gao Y, He Z, Filbin MT (2002) Myelinassociated glycoprotein interacts with the Nogo66 receptor to inhibit neurite outgrowth. Neuron 35:283-290.

Fahrig T, Probstmeier R, Spiess E, Meyer-Franke A, Kirchhoff F, Drescher B, Schachner M (1993) Functional topography of the myelin-associated glycoprotein. I. Mapping of domains by electron microscopy. Eur J Neurosci 5:1118-1126.

Filbin MT (2003) Myelin-associated inhibitors of axonal regeneration in the adult mammalian CNS. Nat Rev Neurosci 4:703-713.

Freigang J, Proba K, Leder L, Diederichs K, Sonderegger P, Welte W (2000) The crystal structure of the ligand binding module of axonin-1/TAG-1 suggests a zipper mechanism for neural cell adhesion. Cell 101:425-433.

Fruttiger M, Montag D, Schachner M, Martini R (1995) Crucial role for the myelin-associated glycoprotein in the maintenance of axon-myelin integrity. Eur J Neurosci 7:511-515.
Kelm S, Pelz A, Schauer R, Filbin MT, Tang S, de Bellard ME, Schnaar RL, Mahoney JA, Hartnell A, Bradfield P, Crocker PR (1994) Sialoadhesin, myelin-associated glycoprotein and CD22 define a new family of sialic acid-dependent adhesion molecules of the immunoglobulin superfamily. Curr Biol 4:965-972.

Kelm S, Schauer R, Crocker PR (1996) The Sialoadhesins—a family of sialic acid-dependent cellular recognition molecules within the immunoglobulin superfamily. Glycoconj J 13:913-926.

Li C, Tropak MB, Gerlai R, Clapoff S, Abramow-Newerly W, Trapp B, Peterson A, Roder J (1994) Myelination in the absence of myelin-associated glycoprotein. Nature 369:747-750.

Liu BP, Fournier A, GrandPre T, Strittmatter SM (2002) Myelin-associated glycoprotein as a functional ligand for the Nogo-66 receptor. Science 297:1190-1193.

Marta CB, Taylor CM, Cheng S, Quarles RH, Bansal R, Pfeiffer SE (2004) Myelin associated glycoprotein cross-linking triggers its partitioning into lipid rafts, specific signaling events and cytoskeletal rearrangements in oligodendrocytes. Neuron Glia Biol 1:35-46.

McKerracher L, David S, Jackson DL, Kottis V, Dunn RJ, Braun PE (1994) Identification of myelin-associated glycoprotein as a major myelinderived inhibitor of neurite growth. Neuron 13:805-811.

Meyer-Franke A, Tropak MB, Roder JC, Fischer P, Beyreuther K, Probstmeier R, Schachner M (1995) Functional topography of myelin-associated glycoprotein. II. Mapping of domains on molecular fragments. J Neurosci Res 41:311-323.

Mi S, Lee X, Shao Z, Thill G, Ji B, Relton J, Levesque M, Allaire N, Perrin S, Sands B, Crowell T, Cate RL, McCoy JM, Pepinsky RB (2004) LINGO-1 is a component of the Nogo-66 receptor/p75 signaling complex. Nat Neurosci 7:221-228.

Montag D, Giese KP, Bartsch U, Martini R, Lang Y, Bluthmann H, Karthigasan J, Kirschner DA, Wintergerst ES, Nave KA, Zielaser J, Toyka KV, Lipp HP, Schachner M (1994) Mice deficient for the myelin-associated glycoprotein show subtle abnormalities in myelin. Neuron 13:229-246.

Mukhopadhyay G, Doherty P, Walsh FS, Crocker PR, Filbin MT (1994) A novel role for myelin-associated glycoprotein as an inhibitor of axonal regeneration. Neuron 13:757-767.

Norton WT, Poduslo SE (1973) Myelination in rat brain: method of myelin isolation. J Neurochem 21:749-757.

Pan B, Fromholt SE, Hess EJ, Crawford TO, Griffin JW, Sheikh KA, Schnaar RL (2005) Myelin-associated glycoprotein and complementary axonal ligands, gangliosides, mediate axon stability in the CNS and PNS: neuropathology and behavioral deficits in single- and double-null mice. Exp Neurol 195:208-217.

Park JB, Yiu G, Kaneko S, Wang J, Chang J, He Z (2005) A TNF receptor family member, TROY, is a coreceptor with Nogo receptor in mediating the inhibitory activity of myelin inhibitors. Neuron 45:345-351.

Quarles RH, Johnson D, Brady RO, Sternberger NH (1981) Preparation and characterization of antisera to the myelin-associated glycoprotein. Neurochem Res 6:1115-1127.

Salzer JL, Pedraza L, Brown M, Struyk A, Afar D, Bell J (1990) Structure and function of the myelin-associated glycoproteins. Ann NY Acad Sci 605:302-312.

Shao Z, Browning JL, Lee X, Scott ML, Shulga-Morskaya S, Allaire N, Thill G, Levesque M, Sah D, McCoy JM, Murray B, Jung V, Pepinsky RB, Mi S (2005) TAJ/TROY, an orphan TNF receptor family member, binds Nogo-66 receptor 1 and regulates axonal regeneration. Neuron 45:353-359.

Sheikh KA, Sun J, Liu Y, Kawai H, Crawford TO, Proia RL, Griffin JW, Schnaar RL (1999) Mice lacking complex gangliosides develop Wallerian degeneration and myelination defects. Proc Natl Acad Sci USA 96:7532-7537.

Shen YJ, DeBellard ME, Salzer JL, Roder J, Filbin MT (1998) Myelinassociated glycoprotein in myelin and expressed by Schwann cells inhibits axonal regeneration and branching. Mol Cell Neurosci 12:79-91.

Su XD, Gastinel LN, Vaughn DE, Faye I, Poon P, Bjorkman PJ (1998) Crystal structure of hemolin: a horseshoe shape with implications for homophilic adhesion. Science 281:991-995.

Tang S, Shen YJ, DeBellard ME, Mukhopadhyay G, Salzer JL, Crocker PR, Filbin MT (1997) Myelin-associated glycoprotein interacts with neurons via a sialic acid binding site at ARG118 and a distinct neurite inhibition site. J Cell Biol 138:1355-1366.

Trapp BD (1988) Distribution of the myelin-associated glycoprotein and P0 
protein during myelin compaction in quaking mouse peripheral nerve. J Cell Biol 107:675-685.

Trapp BD (1990) Myelin-associated glycoprotein. Location and potential functions. Ann NY Acad Sci 605:29-43.

Venkatesh K, Chivatakarn O, Lee H, Joshi PS, Kantor DB, Newman BA, Mage R, Rader C, Giger RJ (2005) The Nogo-66 receptor homolog NgR2 is a sialic acid-dependent receptor selective for myelin-associated glycoprotein. J Neurosci 25:808-822.

Vinson M, van der Merwe PA, Kelm S, May A, Jones EY, Crocker PR (1996) Characterization of the sialic acid-binding site in sialoadhesin by sitedirected mutagenesis. J Biol Chem 271:9267-9272.

Vinson M, Strijbos PJ, Rowles A, Facci L, Moore SE, Simmons DL, Walsh FS (2001) Myelin-associated glycoprotein interacts with ganglioside GT1b. A mechanism for neurite outgrowth inhibition. J Biol Chem 276: 20280-20285.

Vinson M, Rausch O, Maycox PR, Prinjha RK, Chapman D, Morrow R, Harper AJ, Dingwall C, Walsh FS, Burbidge SA, Riddell DR (2003) Lipid rafts mediate the interaction between myelin-associated glycoprotein (MAG) on myelin and MAG-receptors on neurons. Mol Cell Neurosci 22:344-352.

Vyas AA, Patel HV, Fromholt SE, Heffer-Lauc M, Vyas KA, Dang J, Schachner M, Schnaar RL (2002) Gangliosides are functional nerve cell ligands for myelin-associated glycoprotein (MAG), an inhibitor of nerve regeneration. Proc Natl Acad Sci USA 99:8412-8417.

Vyas AA, Blixt O, Paulson JC, Schnaar RL (2005) Potent glycan inhibitors of myelin-associated glycoprotein enhance axon outgrowth in vitro. J Biol Chem 280:16305-16310.

Wang KC, Koprivica V, Kim JA, Sivasankaran R, Guo Y, Neve RL, He Z (2002a) Oligodendrocyte-myelin glycoprotein is a Nogo receptor ligand that inhibits neurite outgrowth. Nature 16:16.

Wang KC, Kim JA, Sivasankaran R, Segal R, He Z (2002b) P75 interacts with the Nogo receptor as a co-receptor for Nogo, MAG and OMgp. Nature 420:74-78.

Wong ST, Henley JR, Kanning KC, Huang KH, Bothwell M, Poo MM (2002) A p75(NTR) and Nogo receptor complex mediates repulsive signaling by myelin-associated glycoprotein. Nat Neurosci 5:1302-1308.

Yamashita T, Higuchi H, Tohyama M (2002) The p75 receptor transduces the signal from myelin-associated glycoprotein to Rho. J Cell Biol 157:565-570.

Yang LJ, Lorenzini I, Vajn K, Mountney A, Schramm LP, Schnaar RL (2006) Sialidase enhances spinal axon outgrowth in vivo. Proc Natl Acad Sci USA 103:11057-11062.

Yiu G, He Z (2006) Glial inhibition of CNS axon regeneration. Nat Rev Neurosci 7:617-627. 